$2 n=54$ chromosomes, thus suggesting that, despite multivalent and univalent formation, the species was fairly balanced in respect of chromosome number. Of the plants raised from the seed set on the crossed ears, all but one were matromorphic. The single hybrid plant possessed $2 n=41$ chromosomes. During meiosis in the pollen-mother-cells of the hybrid 32 out of 36 clearly analysable cells showed 16 bivalents and 9 univalents; the remaining four cells showed 14-15 bivalents and 11-13 univalents per cell.

From the number of chromosomes and from the most frequent mode of chromosome association observed in the hybrid during meiosis it would appear that the hybrid plant arose from the union of an unreduced 14-chromosome typhoides-gamete with a normal 27-chromosome squamulatum-gamete. It would also appear that, of the 16 bivalents observed in the hybrid, 7 were derived from the typhoidesparent and 9 from autosyndetic pairing in the 18 out of the 27-chromosome complement derived from the squamulatum-parent. These observations further suggest that $P$. squamulatum $(2 n=54)$ is an autoallopolyploid ${ }^{4}$ comprising in its somatic complement a 9-chromosome genome represented in the autotetraploid condition and another 9-chromosome genome in the diploid condition. Supporting evidence for such a view is obtained from the study of meiotic chromosome behaviour in $P$. squamulatum, where as many as 8 quadrivalents, out of the possible 9 , were noticed in two cells.

B. D. Patit

M. W. Hardas

Division of Botany,

A. B. Joshr

Indian Agricultural Research Institute, New Delhi, 12.

1 "Index Kewensis", 11, 459 (1893).

${ }^{2}$ Joshi, A. B., and Patil, B. D., Proc. Eighth Internat. Grassland Congr., Reading, 1960 (in the press).

${ }^{3}$ Raman, V. S., Chandrasekharan, P., and Krishnaswamy, D., Curr Sci., 28, 127 (1959).

"Stebbins, jun., G. L., "Variation and Evolution in Plants", 315 (1950).

\section{A Simplified Method for the Study of Chromosomes in Man}

Bottura and Ferrari ${ }^{1}$ have described recently a rapid technique for the cytological preparation of human chromosomes, which involves intravenous injections of deacetylmethylcolchicine $2 \mathrm{hr}$. prior to a sternal marrow puncture. The marrow is then treated with hypotonic citrate, hydrolysed and stained. As they rightly point out, there are some advantages in this rapid technique over the short- or long-term tissue culture.

We have been employing similar techniques and have obtained good preparations of human chromosomes from dividing cells in the sternal marrow by giving the patient $1 \mathrm{mgm}$. of colchicine intravenously $1 \mathrm{hr}$. before the puncture. The material is then placed in 0.72 per cent $\mathrm{w} / \mathrm{v}$ sodium citrate for $10 \mathrm{~min}$., fixed in 3:1 (ethanol acetic), hydrolysed for $6 \mathrm{~min}$. in $N$ hydrochloric acid and stained in orcein (Fig. 1). Satisfactory preparations have also boen made without giving the colchicine, relying only on the action of the hypotonic citrate; although, as would be expected, the contraction of the chromosomes is not then so well developed.

These simple procedures are extremely useful for the rapid screening of human material. They would

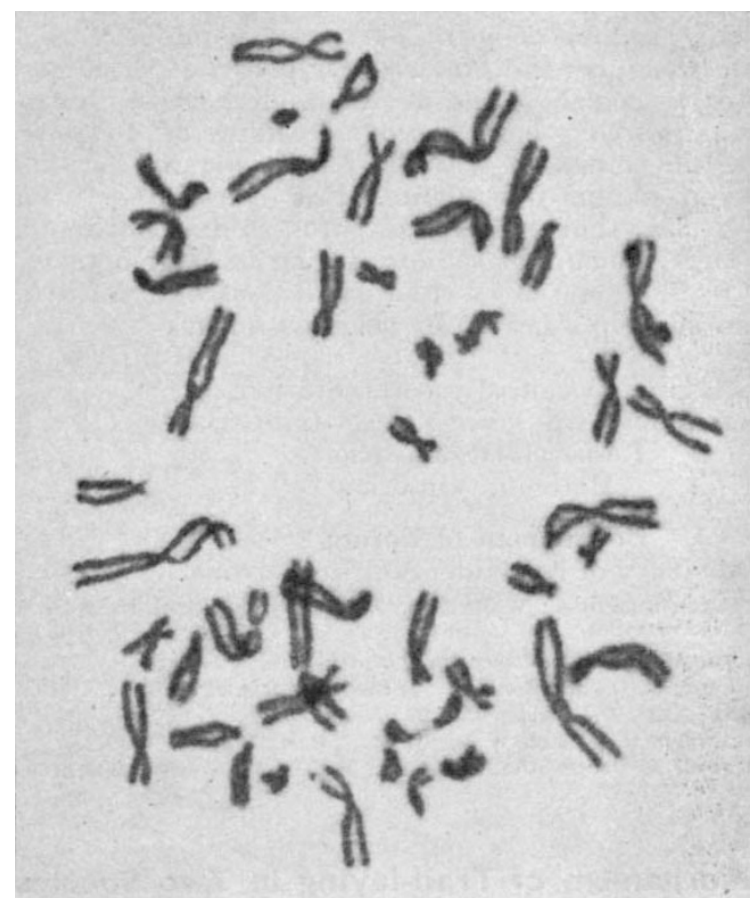

Fig. 1

suffer perhaps from the disadvantage that they may not detect a chimærical situation. Their outstanding advantage, however, is the establishment of the in vivo situation in conditions such as leukrmia, where the results of culture techniques may not be truly representative.

M. A. Kinlovgh

H. N. Robson

Department of Medicine,

\section{L. HAYMAN}

Department of Genetics,

University of Adelaide.

${ }^{1}$ Bottura, C., and Ferrari, I., Nature, 186, 904 (1960).

\section{Use of Induced Rooting in Cytological Studies}

THE common practice for the study of somatic chromosomes is to cut sections or squash the growing root-tips of a seedling. Occasionally successful preparations of somatic chromosomes have also been made from very young leaves and buds, but still in most cases root-tips continue to be favourite material for the study of somatic chromosomes. Seeds of wild plants, however, unlike those of the cultivated ones, are not always easily available, and this accounts at least in part for the fact that chromosome number in members of the former group have either not been determined or, if determined at all, reported from meiotic studies. This is evident from a cursory examination of the "Chromosome Atlas of Flowering Plants"1. The present work was started to find if these difficulties could be overcome by inducing adventitious root formation in isolated shoots and leaves by means of treatment with various growth-promoting substances. 